\title{
Pain threshold in the masticatory and cervical muscles in different types of temporomandibular disorders
}

\author{
Nattalia de Oliveira', Ana Elisa Zulliani Stroppa Marques², Renata Lumena Altruda Pucci ${ }^{1}$, Érica Almeida Sousa 1 , \\ Flora Tolentino Ribeiro1, Flavia Roberta Faganello Navega², Cristiane Rodrigues Pedroni²
}

\begin{abstract}
Introduction: Given the intimate connection of the temporomandibular joint in the cervical region and its functions of chewing, speech and swallowing, patients with temporomandibular disorders (TMD) have most painful condition in stomathognatic muscles. Objective: Check for differences in pressure pain threshold of the masseter (MS), temporalis (TM), upper trapezius (UT) and sternocleidomastoid (SCM) muscles in different types of TMD. Method: Participated in the research 97 subjects, classified according to "The Research Diagnostic Criteria for Temporomandibular Disorders (RDC/TMD)": myofascial pain (TMD IA), myofascial pain with limited opening (TMD IB), disc displacement with reduction (TMD IIA), disc displacement without reduction and with limited opening (TMD IIB), disc displacement without reduction and without limited opening (TMD IIC). For measurement of the pressure pain threshold (PPT) was used the pressure algometry program $\left(\operatorname{Kratos}^{\circledR}\right)$ of the TM, MS, UT and SCM muscles. For statistical analysis was used the Graphpad Instat program with the Kruskal-Wallis test. Results: The sample consisted of 67 women and 30 men with an average age of $22.09 \pm 5.45$ years. Of these subjects, 40 were classified as "with TMD", 57 as "without TMD", 34 as "TMD IA", 16 as "TMD IB", 14 as "TMD IIA" and nobody as "TMD IIB" and "TMD IIC". The MS, TM and UT muscles showed decreased threshold in myogenic groups of TMD with relation to the group without TMD. Only the masseter muscle showed statistical significance when compared to the myogenic groups with each other, demonstrating that the IB group has lower PPT. Individuals with TMD IB showed lower PPT of MS, TM and UT muscles when compared to TMD IIA. Conclusion: There is a significant difference comparing the PTT of MS, TM and UT muscles of myofascial pain subgroup to the subgroup without TMD. There were differences between the groups myogenic in PPT of MS. TMD IB showed lower threshold in TMD IB group than in TMD IIA group. Controversially, it was not observed when comparing the SCM muscle and disc displacement subgroup with the subgroup without TMD.
\end{abstract}

Keywords: stomatognathic system, evaluation, pain

\section{INTRODUCTION}

The temporomandibular joint (TMJ) has connection with the skull base, ligament and muscle connections and the cervical region, forming the cranio-cervico-mandibular system that requires a structural alignment to maintain the balance of the muscles involved. ${ }^{(1-3)}$

The temporomandibular disorder (TMD) constitutes a group of diseases that affect the masticatory muscles, TMJ and associated structures. Its signs and symptoms range from facial and ear pain, headache, joint noises, mandibular range of motion restriction, joint tenderness and muscle and cervical spine disorders. $(1,2,4,5)$

The TMD is the second most frequent cause of orofacial pain, observed in $5.3 \%$ of the population, with a higher incidence in women with $19-45$ years. Of the total population, $40-75 \%$ show a symptom and $33 \%$ a sign of this dysfunction. ${ }^{(4)}$ Pain from TMD has a negative impact on quality of life of individuals with this disease, which interferes mainly in nutrition, sleep, school and work activities. $(6,7)$

Some studies classify TMD as muscular and arthrogenic ${ }^{(8,9)}$, but it is difficult to relate the etiology, so, in 1992 was created the Criteria for Research of Temporomandibular Disorders by the International RDC-TMD Consortium in order to standardize diagnosis, allow comparison between studies, increase epidemiology of TMD and avoid comparison of literature studies. ${ }^{(5,10-12)}$

The hyperactivity of the masticatory muscles corresponds to $80 \%$ of the TMD etiology, which interferes with cervical musculature - sternocleidomastoid (SCM) and upper

Corresponding Author: Name: Cristiane Rodrigues Pedroni. Address: Av. Higino Muzzi Filho, 737, CEP 17525-900 Marilia, SP - Brazil. Telephone: (14) 3402-1300 / E-mail: pedronicr@marilia.unesp.br

2 Universidade Estadual Paulista "Júlio de Mesquita Filho", Campus Marília, São Paulo, Brazil.

Full list of author information is available at the end of the article.

Financial support: This study was financed by PROEX-UNESP (Pró-Reitoria de Extensão Universitária).

Submission date 29 July 2016; Acceptance date 12 December 2016; Publication online date 27 December 2016 
trapezius (UT). ${ }^{(1,2,13)}$ As an example of interference of a system in other, patients with TMD have greater presence of pain in the aforementioned musculatures. $(2,13,14)$

There are few studies in the literature that studied the pressure pain threshold (PPT) of the muscles related to TMD. Farella et al ${ }^{(15)}$ report that the masseter (MS) and temporal (TM) in people with TMD has lower pain threshold than those without the disorder. However, few studies have identified the PPT in UT and SCM and others that related the diagnosis of the RDC/TMD. Therefore, this study aimed to analyze whether there are differences in the PPT of the MS, TM, UT and SCM muscles between subjects with and without TMD and in the different classifications of the dysfunction.

\section{METHOD}

The Human Research Ethics Committee of the Faculty of Philosophy and Science of UNESP from Marília (2013-746 protocol) approved the research.

The research was conducted in the Laboratory of Musculoskeletal Assessment of Education and Health Studies Center (CEES) in the city of Marilia - SP. Individuals were randomly selected in a sample of college students. The participants were 97 people (67 women and 30 men) with no previous diagnosis of TMD. Subjects who used orthopedic functional or orthodontic device, fixed or removable prosthesis, performed surgical procedure in the temporomandibular region and cervical spine and who used painkillers, anti-inflammatories, muscle relaxants or antidepressants were not included in this study. And before performing any procedure the participants signed a Free, Prior and Informed Consent term agreeing to participate in the research. There was no sample loss during the time of the research.

For classification of the type of TMD was used RDC/TMD axis I translated and adapted for the Brazilian population which was conducted by a single evaluator. This diagnostic system is not hierarchical and allows the possibility of multiple diagnoses for the same individual. For its realization the following material was used: rubber gloves and a Starrett ${ }^{\circledR}$ digital caliper. The following classifications of this system were used for the TMD subgroups: myofascial pain (TMD IA), myofascial pain with limited opening (TMD IB); disc displacement with reduction (TMD IIA), disc displacement without reduction and with limited opening (TMD IIB), disc displacement without reduction and without limited opening (TMD IIC). ${ }^{(16)}$ All the people who fitted into the diagnosis of TMD were grouped in "With TMD" and the people who did not fitted into any of the diagnosis were grouped in "Without TMD".

For measurement of the PPT was used a Kratos ${ }^{\circledR}$ pressure algometry containing a bar with a flat circular tip and diameter of $1.0 \mathrm{~cm}^{2}$, digital reading and precision of $0.005 \mathrm{Kg}$, allowing the collection of PPT values in TM (anterior fibers), MS (masseter body), UT and SCM (muscle belly) muscles bilaterally which were perpendicular to the muscle fibers, performed by a blinded investigator, applying a pressure measured in kilogram-force (kgf) increasing at each point until the moment that the subject referred the presence of pain.

To compare the PPT data was used the Graphpad Instat ${ }^{\circledR}$ program with the Kruskal-Wallis test followed by the Dunn posttest.

\section{RESULTS}

Table 1 shows the characterization of the subject facing the RDC/TMD with age and number of men and women in each classification. It is noted that in this population no subject fitted into the IIB and IIC classifications.

Table 2 describes the PPT values found between the groups with TMD and the without TMD group. MS, TM and UT muscles showed lower thresholds in myogenic TMD groups in relation to the group without TMD. Only the masseter muscle showed statistical significance when comparing the myogenic groups

Table 1. Age and number of subjects (men and women) in the classifications of RDC/TMD.

\begin{tabular}{|c|c|c|c|c|c|}
\hline & WITHOUT TMD & WITH TMD & TMD IA & TMD IB & TMD IIA \\
\hline Age & $22.20 \pm 6.05$ & $22.02 \pm 5.05$ & $22.35 \pm 5.78$ & $21.81 \pm 4.31$ & $21.29 \pm 1.98$ \\
\hline № Women & $17(42.5 \%)$ & $13(22.8)$ & $6(17.7 \%)$ & $1(6.2 \%)$ & $6(42.9 \%)$ \\
\hline № Men & $40(41.24 \%)$ & $57(58.76)$ & $34(100 \%)$ & $16(100 \%)$ & $14(100 \%)$ \\
\hline Total № & $23(57.5 \%)$ & $44(77.2 \%)$ & $28(82.3 \%)$ & $15(93.8 \%)$ & $8(57.1 \%)$ \\
\hline
\end{tabular}

Age values expressed in mean, standard deviation and percentage.

Table 2. PPT (kgf) in the classifications of RDC/TMD.

\begin{tabular}{lccc}
\hline & WITHOUT TMD & TMD IA & TMD IB \\
\hline SCM & $1.50 \pm 0.73$ & $1.30 \pm 0.59$ & $1.42 \pm 1.14$ \\
Masseter & $2.18 \pm 0.81$ & $1.80 \pm 0.63 * ¥$ & $1.36 \pm 0.33 * \diamond$ \\
Temporal & $2.75 \pm 1.21$ & $2.16 \pm 0.94$ & $1.71 \pm 0.42 * \diamond$ \\
Trapezius & $4.98 \pm 2.08$ & $3.12 \pm 0.77 *$ & $3.19 \pm 1.26 * \diamond$ \\
\hline
\end{tabular}

PPT values expressed in mean and standard deviation. SCM: sternocleidomastoid. Comparison of the groups in relation to WITHOUT TMD with $p<0.05(*)$. Comparison of the TMD IA group with the TMD IB group with $p<0.05$ (¥). Comparison of the TMD IB group with the TMD IIA group with $p<0.05(0)$. 
among themselves, demonstrating that the IB group has lower PPT. The individuals with TMD IB showed lower PPT in MS, TM and UT muscles when compared to TMD IIA.

\section{DISCUSSION}

Our study had as main findings that there is difference of PPT in MS, TM and UT muscles of TMD IA and TMD IB subgroups when compared with the subgroup WITHOUT TMD and that the PPT of MS is lower in TMD IB group compared to IA and IIA group. And TMD IB subgroup has a lower threshold in MS, TM and UT muscles compared to TMD IIA group. In contrast, the same was not observed when comparing the SCM muscle with any group and IIA subgroup with the subgroup WITHOUT TMD.

In this study, $58 \%$ of the volunteers had some subtype of TMD. Similar results were also found in other studies with university students, a group that shows risk, possibly by the performance charging level in academic stage. ${ }^{(17-20)}$ However, these do not use RDC/TMD as a diagnostic tool.

It was also noted that the female was more rated with TMD, a finding that agrees with the literature, which is probably related to differences between genders such as muscle structure, higher level of anxiety, hormonal changes and increased sensitivity to noxious stimuli. ${ }^{(17,18,20-24)}$

The study showed significant differences when comparing the PTT of the masticatory muscles (MS and TM) and UT and showed no significant difference in the SCM muscle of myogenic subgroups with the subgroup WITHOUT TMD. Regarding the masticatory muscles, Farella et al (15) and Moreno et al ${ }^{(25)}$ also found lower PPT in subjects with TMD. As for the SCM and UT muscles are few studies which studied the PPT between subjects with and without TMD, although they had connections with the TMD for acting as the head stabilizers and have activity during the stomatognathic functions. $^{(3,26,27)}$ Different from this study, Milanesi et al (26) and Moreno et al ${ }^{(25)}$ found a significant difference in the SCM muscle, but these studies have different methodologies of ours, the first one used palpation as a diagnostic method for PPT and in the second one the sample had headache in addition to TMD. However, for the UT muscle, Chen et al ${ }^{(28)}$ and Moreno et al ${ }^{(25)}$ found, as in this study, significant difference in PPT between people with and without TMD.

Also showed no significant difference when comparing the IIA subgroup with the subgroup WITHOUT TMD, possibly for having joint involvement. ${ }^{(16)}$

Thus, the research is relevant in order to point the need for more studies that cover the PPT of the aforementioned muscles and compare them with the classifications of the RDC/TMD.

\section{CONCLUSION}

Given the above, it is concluded that the pain thresholds of MS, TM and UT muscles are smaller in subjects with myogenic TMD compared to the subjects without TMD. Among the subgroups of myogenic TMD were found lower PPT values for the same muscles when the TMD had muscle impairment to limited opening compared to the arthrogenic TMD. The muscular subgroups only showed significant differences in PPT of MS muscle. It was not observed any difference to the SCM muscle.

\section{AUTHOR'S CONTRIBUTIONS}

Oliveira N - Data collection and preparation of the manuscript

Stroppa-Marques AEZ - Preparation of the manuscript

Pucci RLA - Data collection

Sousa EA - Data collection

Tolentino F - Data collection

Faganello-Navega FR - Co-advisor

Pedroni CR - Advisor

\section{CONFLICT OF INTEREST}

The authors declare that they have no conflicts of interest.

\section{AUTHOR DETAILS}

${ }^{1}$ Universidade Estadual Paulista "Júlio de Mesquita Filho", Campus Marília, São Paulo, Brazil.

\section{REFERENCES}

1. Grade R, Caramês J, Pragosa A, Carvalhão J, Sousa S. Postura e Disfunção Temporo-Mandibular, Controvérsias Actuais. Rev Port Estomatol Cir Maxilofac. 2008;49:111-117.

2. Olivo SA, Bravo J, Magee DJ, Thie NM, Major PW, Flores-Mir C. The association between head and cervical posture and temporomandibular disorders: a systematic review. J Orofac Pain. 2006;20(1):9-23.

3. Motoyoshi M, Shimazaki T, Sugai T, Namura S. Biomechanical influences of head posture on occlusion: an experimental study using element analysis. Eur J Orthod. 2002;24(4):319-326.

4. Carrara SV, Conti PCR, Barbosa JS. Termo do 10 Consenso em Disfunção Temporomandibular e Dor Orofacial. Dental Press J Orthod. 2010;15(3):114-112.

5. Manfredini D, Bucci MB, Nardini LG. The diagnostic process for temporomandibular disorders. Stomatologija. 2007;9(2):35-39.

6. Oliveira AS, Bermudez CC, Souza RA, Souza CMF, Dias EM Castro CES, et al. Impacto da Dor na Vida de Portadores de Disfunção Temporomandibular. J appl oral sci. 2013;11(2):138-43.

7. Kuroiwa DN, Marinelli JG, Rampani MS, Oliveira W, Nicodemo D. Desordens temporomandibulares e dor orofacial: estudo da qualidadede vida medida pelo Medical Outcomes Study 36 - Item Short Form Health Survey. Rev dor. 2011;12(2):93-98.

8. American Society of Temporomandibular Joint Surgeons. Guidelines for diagnosis and management of disorders involving the temporomandibular joint and related musculoskeletal structures. Cranio. 2003;21(1):68-76.

9. Rodrigues-Bigaton D, Berto R, Oliveira AS, Bérzin F. Does masticatory muscle hyperactivity occur in individuals presenting temporomandibular disorders? Braz j oral sci. 2008;7(24):1497-1501.

10. Manfredini D, Guarda-Nardini L, Winocur E, Piccotti F, Ahlberg J, Lobbezoo F. Research diagnostic criteria for temporomandibular disorders: a systematic review of axis I epidemiologic findings. Oral Surg Oral Med Oral Pathol Oral Radiol Endod. 2011;112(4):453-462

11. Steenks MH, de Wijer A. Validity of the Research Diagnostic Criteria for Temporomandibular Disorders Axis I in clinical and research settings. J Orofac Pain. 2009;23(1):9-16.

12. Dworkin SF, LeResche L. Research diagnostic criteria for temporomandibular disorders: review, criteria, examinations and specifications, critique. J Craniomandib Disord. 1992;6(4):301-355. 
13. Pallegama RW, Ranasinghe AW, Weerasinghe VS, Sitheeque MA. Influence of masticatory muscle pain on electromyographic activities of cervical muscles in patients with myogenous temporomandibular disorders. J Oral Rehabil. 2004;31(5):423-429.

14. Wright EF. Referred craniofacial pain patterns in patients with temporomandibular disorder. J Am Dent Assoc. 2000;131(9):1307-1315.

15. Farella M, Michelotti A, Steenks MH, Romeo R, Cimino R, Bosman F. The diagnostic value of pressure algometry in myofascial pain of the jaw muscles. J Oral Rehabil. 2000;27(1):9-14.

16. Pereira Júnior FJ, Favilla EE, Dworkin S, Huggins K. Critérios de diagnóstico para pesquisa das disfunções temporomandibulares (RDC/TMD). Tradução oficial para a língua portuguesa / Research diagnostic criteria for temporomandibular disorders (RDC/TMD): formal translation to portuguese. JBC j bras clin odontol integr. 2004;8(47):384-395.

17. Bezerra BPN, Ribeiro AIAM, Farias AB, Lira FABL, Fontes LBC, Nascimento SR, et al. Prevalência da disfunção temporomandibular e de diferentes níveis de ansiedade em estudantes universitários. Rev dor. 2012;13(3): 235-242.

18. Oliveira AS, Grossi DB, Dias EM. Sinais e sintomas da disfunção temporomandibular nas diferentes regiões brasileiras. Fisioter pesqui. 2008;15(4):392-396.

19. Oliveira AS, Dias EM, Contato RG, Berzin F. Prevalence study of signs and symptoms of temporomandibular disorder in Brazilian college students. Braz oral res. 2006;20(1):3-7.

20. Pedroni CR, De Oliveira AS, Guaratini MI. Prevalence study of signs and symptoms of temporomandibular disorders in university students. J Oral Rehabil. 2003;30(3):283-289.
21. Geres GS, Célia CAS, Masselli MR, Ferreira DMA, Gomes DCA, Pachioni FSM, et al. Análise de condições clínicas em estudantes com disfunção temporomandibular. Ter Man. 2013;11(53):319-326

22. Fillingim RB, King CD, Ribeiro-Dasilva MC, Rahim-Williams B, Riley JL 3rd. Sex, gender, and pain: a review of recent clinical and experimental findings. J Pain. 2009;10(5):447-485

23. Greenspan JD, Craft RM, LeResche L, Arendt-Nielsen L, Berkley KJ, Fillingim $\mathrm{RB}$, et al. Studying sex and gender differences in pain and analgesia: a consensus report. Pain. 2007;132 Suppl 1:S26-45.

24. Wiesenfeld-Hallin Z. Sex differences in pain perception. Gend Med. 2005;2(3):137-145.

25. Moreno BGD, Maluf SA, Marques AP, Crivello-Júnior O. Avaliação clínica e da qualidade de vida de indivíduos com disfunção temporomandibular. Rev bras fisioter. 2009;13(3):210-214.

26. Milanesi JM, Corrêa ECR, Borin GS, Souza JA, Pasinato F. Atividade elétrica dos músculos cervicais e amplitude de movimento da coluna cervical em indivíduos com e sem DTM. Fisioter Pesqui. 2011;18(4):317-322.

27. Chandu A, Suvinen TI, Reade PC, Borromeo GL. Electromyographic activity of frontalis and sternocleidomastoid muscles in patients with temporomandibular disorders. J Oral Rehabil. 2005;32(8):571-6.

28. Chen H, Slade G, Lim PF, Miller V, Maixner W, Diatchenko L. Relationship between temporomandibular disorders, widespread palpation tenderness, and multiple pain conditions: a case-control study. J Pain. 2012;13(10):1016-27 